\title{
8
}
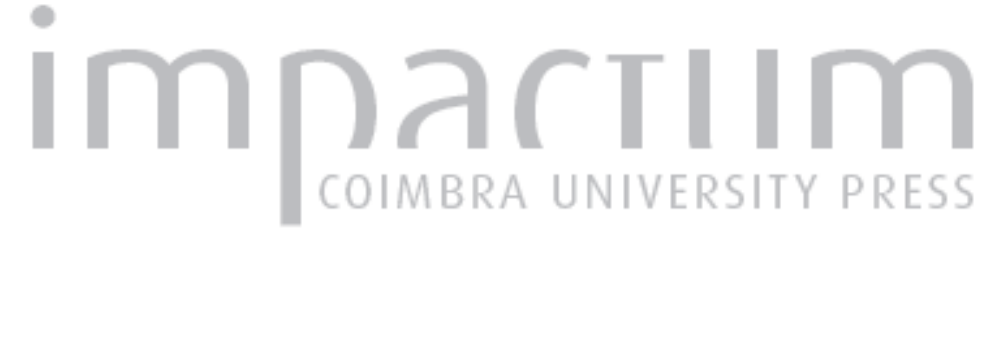

\section{Páginas de Suetónio: o último dia do artifex Nero}

\section{Autor(es): Brandão, José Luís}

URL

persistente:

URI:http://hdl.handle.net/10316.2/30470

DOI:

DOI:http://dx.doi.org/10.14195/0872-2110_49_7

Accessed : $\quad$ 26-Apr-2023 12:37:03

A navegação consulta e descarregamento dos títulos inseridos nas Bibliotecas Digitais UC Digitalis, UC Pombalina e UC Impactum, pressupõem a aceitação plena e sem reservas dos Termos e Condições de Uso destas Bibliotecas Digitais, disponíveis em https://digitalis.uc.pt/pt-pt/termos.

Conforme exposto nos referidos Termos e Condições de Uso, o descarregamento de títulos de acesso restrito requer uma licença válida de autorização devendo o utilizador aceder ao(s) documento(s) a partir de um endereço de IP da instituição detentora da supramencionada licença.

Ao utilizador é apenas permitido o descarregamento para uso pessoal, pelo que o emprego do(s) título(s) descarregado(s) para outro fim, designadamente comercial, carece de autorização do respetivo autor ou editor da obra.

Na medida em que todas as obras da UC Digitalis se encontram protegidas pelo Código do Direito de Autor e Direitos Conexos e demais legislação aplicável, toda a cópia, parcial ou total, deste documento, nos casos em que é legalmente admitida, deverá conter ou fazer-se acompanhar por este aviso. 


\section{Boletim de}

\section{Estudos Clássicos}

Associação Portuguesa de Estudos Clássicos Instituto de Estudos Clássicos

Coimbra

Junho de 2008 


\section{Páginas de Suetónio O ÚlTIMO DiA DO ARTIFEX NERO}

\section{O contexto}

O episódio da morte de Nero é talvez a melhor secção narrativa de Suetónio e das mais conhecidas. Este relato aparece no culminar de um longo processo que começa com a notícia da revolta de Víndex, na Gália (Nero 40). Mas, para melhor compreender o trecho proposto (Nero 47.3-49.4), devemos ter em conta que a revolta contra Nero se apresenta como o desenlace natural do seu comportamento tirânico e histriónico (Nero 40.1): talem principem paulo minus quattuordecim annos perpessus terrarum orbis tandem destituit ${ }^{1}$ («Após ter suportado tal príncipe pouco menos que catorze anos, o orbe da terra destituiu-o finalmente»).

As capacidades artísticas de Nero, continuamente presentes no todo desta Vida, entrelaçam-se também com o conteúdo das rubricas relativas à morte. Como é habitual neste contexto, Suetónio faz referência a presságios. Perante a predição dos astrólogos de que seria destituído, Nero afirmava, em grego, que a sua arte o alimentaria, para se desculpar do afinco com que cultivava a arte da cítara (Nero 40.2), inconsciente perante os vários sinais funestos que lhe anunciam a catástrofe.

Faz-se menção de um oráculo de Apolo que o aconselha a acautelar-se do ano setenta e três: Nero julga que será esta a idade da sua morte, quando, na verdade, o presságio se refere à idade actual de $\mathrm{Galba}^{2}$. O biógrafo sublinha o contraste entre o engano e a confiança excessiva de Nero que, depois de perder num naufrágio bens de grande valor, não hesita em dizer que «os peixes lhos devolveriam», assimilando à sua pessoa a conhecida lenda do rico Polícrates, tirano de Samos (Hdt. 3.39-43).

Uma impressionante coincidência, que só Suetónio refere, é o facto de Nero receber a notícia da revolta da Gália no mesmo dia em que, anos antes, mandara matar a mãe (Nero 40.4): fica sugerido o castigo do ímpio, que até

${ }^{1}$ Também o início da narrativa da morte de Calígula é semelhante (Cal. 56): Ita bacchantem atque grassantem non defuit plerisque animus adoriri.

${ }^{2}$ Embora o cálculo da idade de Galba estivesse errado: teria 71 anos em 68. 
representara os papéis de Orestes Matricida e de Édipo Cego (Nero 21. 3). Mas Nero prefere continuar a dedicar-se às suas actividades habituais, como a ginástica e sobretudo a música. As injuriosas missivas de Víndex não lhe doem tanto quanto a acusação de ser mau citaredo e de ser apelidado de Aenobarbo em vez de Nero (Nero 41.1). E pergunta continuamente a todos se conheciam melhor executante do que ele.

Perante a gravidade dos acontecimentos (Nero 41.2), Nero convoca um consilium dos primores, mas trata rapidamente o assunto da reunião e dedica a maior parte do tempo a mostrar as particularidades dos novos órgãos hidráulicos, com a promessa de que «em breve iria apresentar mesmo tudo isto no teatro, se, por acaso, Víndex lho permitisse».

As notícias alarmantes - de que Galba e as Hispânias se tinham juntado à revolta (Nero 42.1) - deixam-no no mais completo desânimo, mas uma nova favorável (Suetónio não diz qual é, mas deve ser a morte de Víndex na batalha de Vesonção) serve de pretexto para cantar versos satíricos, acompanhados de gestos, contra os generais revoltosos, além de continuar a frequentar os espectáculos de teatro em segredo (Nero 42.2). Salientam-se vários projectos congruentes com a crueldade da sua natureza ${ }^{3}$ : assassínios, extermínio do senado, incêndio de Roma, lançar feras contra o povo - uma lista de rumores, surgidos certamente por alturas da revolta ou depois desta, mas sem valor histórico. A inércia alterna com efusivas manifestações de confiança.

Depois de decidir organizar uma expedição contra os revoltosos, Nero afirmou que «mal chegasse à província, se apresentaria, desarmado, à frente dos exércitos e não faria outra coisa senão derramar lágrimas e, depois de reconduzir os revoltosos ao arrependimento, cantaria, no dia seguinte, feliz entre felizes, epinícios, que tinha de compor desde logo» ${ }^{4}$. Por isso, é sua principal preocupação providenciar os carros para o transporte dos órgãos de cena e vestir as concubinas de amazonas, com um corte de cabelo masculino e armadas de machado e de escudo, algo de semelhante ao que o tio Calígula

${ }^{3}$ Nero 43.1: multa et inmania, uerum non abhorrentia a natura sua.

4 Nero 43.2: 'simul ac primum prouinciam attigisset, inermem se in conspectum exercituum proditurum nec quicquam aliud quam fleturum, reuocatisque ad paenitentiam defectoribus insequenti die laetum inter laetos cantaturum epinicia quae iam nunc sibi componi oporteret'. 
já teria feito ${ }^{5}$. Para custear a campanha, impõe com arrogância novas taxas (Nero 44.2).

Diz o biógrafo que Nero especulava com a falta de trigo (Nero 45.1), mas tal afirmação, retirada do contexto político, é uma forma tendenciosa de desacreditar o imperador. O fornecimento de trigo terá sido interrompido por acção de L. Clódio Macro, legado em África, que se insurgira, seguindo o exemplo de Víndex e Galba. A fome causada pela estratégia de Macro desempenha o seu papel, ajudada pela falta de iniciativa de Nero ${ }^{6}$.

O povo, que antes o amava, retira-lhe o apoio, pois a urgência de pão era maior que a de circo, sobretudo quando, durante um período de carência (publica fames), chega um navio de Alexandria, carregado de areia para os lutadores do palácio. O odium expressa-se no conteúdo dos grafitos. Uma das inscrições aponta a arte do imperador como causa da revolta, ao dizer que o seu canto acordara os Galli, numa referência ambígua às aves e ao povo da Gália. E durante a noite, ouvem-se vozes de pessoas que, fingindo altercar com os escravos, reclamam um Vindex 'vingador' (Nero 45.2).

$\mathrm{O}$ imperador mostra-se agora aterrorizado pelos sinais funestos. A conexão da morte de Nero com o assassínio da mãe, da esposa Octávia e do pai (adoptivo) é sublinhada mais uma vez: com ela o biógrafo começa e termina a rubrica dos presságios. Os papéis que Nero interpretara no palco terão influenciado retroactivamente a escrita da sua história, com a ajuda da damnatio memoriae. Depois da morte de Agripina, sonha que lhe arrancam o timão com que governava um navio e que Octávia o arrebata para as densas trevas (Nero 46.1). E, depois de apresentados outros presságios, o biógrafo termina com o último verso da última tragédia cantada por Nero, Édipo no

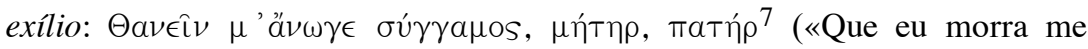
ordena a minha esposa, a minha mãe, o meu pai!»). Suetónio, ao contrário do resto da tradição, considera Nero cúmplice da morte de Cláudio (Nero 33.1). Os fios condutores desta Vida reúnem-se, assim, na narrativa da morte.

Depois, Suetónio retoma a narrativa cronológica, que entretanto abandonara. A notícia da adesão dos restantes exércitos à revolta provoca uma explosão de cólera (Nero 47.1). O biógrafo apresenta-nos a luta interior

5 Nero 43.2. Cf. Cal. 25.3: Caesoniam... ut saepe chlamyde peltaque et galea ornatam ac iuxta adequitantem militibus ostenderit.

${ }^{6}$ Vide Bradley, K. R. (1972) 451-458.

7 Nero 46.3. Díon Cássio, 63.28.3-5, não identifica a peça e liga este verso ao próprio destino de Nero. Vide Bartsch, S. (1994) 43-46. 
de Nero, hesitante entre várias saídas, a adiar as decisões. E, assim, chegamos à última noite do último dos imperadores júlio-cláudios:

\section{O texto}

47.3 Sic cogitatione in posterum diem dilata ad mediam fere noctem excitatus, ut comperit stationem militum recessisse, prosiluit e lecto misitque circum amicos, et quia nihil a quoquam renuntiabatur, ipse cum paucis hospitia singulorum adiit. Verum clausis omnium foribus, respondente nullo, in cubiculum rediit, unde iam et custodes diffugerant, direptis etiam stragulis, amota et pyxide ueneni; ac statim Spiculum murmillonem uel quemlibet alium percussorem, cuius manu periret, requisiit et nemine reperto 'Ergo ego' inquit 'nec amicum habeo, nec inimicum?' procurritque, quasi praecipitaturus se in Tiberim.

48. Sed reuocato rursus impetu aliquid secretioribus latebrae ad colligendum animum desiderauit, et offerente Phaonte liberto suburbanum suum inter Salariam et Nomentanam uiam circa quartum miliarum, ut erat nudo pede atque tunicatus, paenulam obsoleti coloris superinduit adopertoque capite et ante faciem optento sudario equum inscendit, quattuor solis comitantibus, inter quos et Sporus erat. 2 Statimque tremore terrae et fulgure aduerso pauefactus audiit e proximis castris clamorem militum et sibi aduersa et Galbae prospera ominantium, etiam ex obuiis uiatoribus quendam dicentem: 'Hi Neronem persequuntur', alium sciscitantem: 'Ecquid in urbe noui de nerone?' Equo autem ex odore abiecti in uia cadaueris consernato detecta facie agnitus est a quodam missicio praetoriano et salutatus. $3 \mathrm{Vt}$ ad deuerticulum uentum est, dimissis equis inter fruticeta ac uepres per harundineti semitam aegre nec nisi strata sub pedibus ueste ad auersum uillae parietem euasit. Ibi hortante eodem Phaonte, ut interim in specum egestae harenae concederet, negauit se uiuum sub terram iturum, ac parumper commoratus, dum clandestinus ad uillam introitus pararetur, aquam ex subiecta lacuna poturus manu hausit et 'Haec est' inquit, 'Neronis decocta.' 4 Dein diuolsa sentibus paenula traiectos surculos rasit, atque ita quadripes per angustias effossae cauernae receptus in proximam cellam decubuit super lectum modica culcita, uetere pallio strato, instructum; fameque et iterum siti interpellante panem quidem sordidum oblatum aspernatus est, aquae autem tepidae aliquantum bibit.

49. Tunc uno quoque hinc inde instante ut quam primum se impendentibus contumeliis eriperet, scrobem coram fieri imperauit dimensus ad corporis sui modulum, componique simul, si qua inuenirentur, frustra 
marmoris et aquam simul ac ligna conferri curando mox cadaueri, flens ad singula atque identidem dictitans: 'Qualis artifex pereo!'. 2 Inter moras perlatos a cursore Phaonti codicillos praeripuit legitque se hostem a senatu iudicatum et quaeri, ut puniatur more maiorum, interrogauitque, quale id genus esset poenae; et cum comperisset nudi hominis ceruicem inseri furcae, corpus uirgis ad necem caedi, conterritus duos pugiones, quos secum extulerat, arripuit temptataque utriusque acie rursus condidit, causatus nondum adesse fatalem horam. 3 Ac modo Sporum hortabatur, ut lamentari ac plangere inciperet, modo orabat, ut se aliquis ad mortem capessendam exemplo iunaret; interdum segnitiem suam his uerbis increpabat: 'Viuo

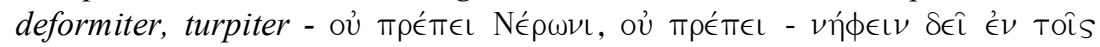

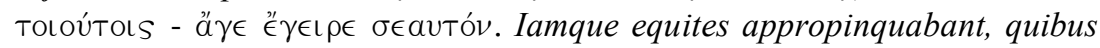
praeceptum erat, ut uiuum eum adtraherent. Quod ut sensit, trepidanter effatus:

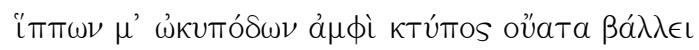

ferrum iugulo adegit iunante Epaphrodito a libellis. 4 Semianimisque adhuc irrumpenti centurioni et paenula ad uulnus adposita in auxilium se uenisse simulanti non aliud respondit quam 'Sero' et 'Haec est fides'. atque in ea uoce defecit, exstantibus rigentibusque oculis usque ad horrorem formidinemque uisentium. Nihil prius aut magis a comitibus exegerat quam ne potestas cuiquam capitis sui fieret, sed ut quoquo modo totus cremaretur. Permisit hoc Icelus, Galbae libertus, non multo ante uinculis exsolutus, in quae primo tumultu coniectus fuerat.

\section{Comentário}

A vivacidade do texto resulta quer dos pormenores quer do estilo claro, com preferência pelas orações curtas, mudanças abruptas de construção e frequente recurso ao ablativo absoluto. D'Anna (1954, 190-194), para quem a variedade estilística de Suetónio se fica a dever à influência de fontes diversas, atribui a elevação do estilo deste relato à influência de uma fonte melhor. Gascou (1984, 685 n. 29) critica D'Anna por não ter percebido que a diferença estilística de Suetónio se explica pela oposição entre as species e a narrativa cronológica: nas primeiras, o biógrafo tende a ser mais repetitivo do que na última.

47.3. O ambiente é de confusão e caos, como mostra o facto de os soldados se desligarem da fides ao imperador e de as sentinelas pilharem antes de se retirarem. A píxide de ouro roubada continha uma poção letal que 
Nero solicitara a Locusta, célebre especialista em venenos (Nero 47.1). Quanto ao gladiador Cláudio Espículo, um dos beneficiados por Nero (Nero 30.2), morreu, depois, às mãos da multidão com a permissão de Galba (Plut. Galba 8.5).

48.1. Nero toma afinal uma direcção oposta à de Óstia, por onde tinha pensado fugir primeiro (Nero 47.1). A especial menção do eunuco Esporo parece servir o fim de lembrar a degradação de Nero: segundo o biógrafo, Nero tomara-o como esposa num casamento segundo as regras (Nero 29), embora haja quem pense que se trataria de deturpação de um ritual ligado a quaisquer mistérios.

48.2 A acumulação de impressões, que transmitem o ponto de vista de Nero, sugerem o medo de um fugitivo perseguido: o tremor de terra e o raio geram um ambiente de terror que deixa Nero pauefactus. O alarido, o cadáver abandonado na rua, as perguntas e boatos sugerem vazio de poder e a ausência de lei.

48.3-4. No cenário da casa de Fáon, as sensações de medo são superadas pela perda da dignitas: o contraste entre a condição anterior e a situação em que se encontra desprovido de tudo: de roupas, de alimentos e de bebida - a ironia da habitação final do construtor da Domus Aurea.

49.1-3. Nero vê-se progressivamente empurrado para a morte. A sugestão do desespero e da aceitação da inevitabilidade do destino e da luta interior é expressa nas citações das palavras entrecortadas do imperador e nas suas hesitações: modo... modo. A ligação da aproximação dos cavaleiros à recitação de um verso da Ilíada mostra que Nero está a morrer como viveu, na procura, qualis artifex, de uma existência épica, resultante da sua megalomania, que o faz misturar a ficção com a realidade, como quando, supostamente, cantava as chamas de Roma, que, segundo Suetónio (Nero 38.2), ele próprio teria ateado. Uma existência que contrasta com a actual caracterização de Nero: nudo pede atque tunicatus; pauefactus; conterritus; e trepidanter effatus.

49.4. A ajuda de Epafrodito será a razão invocada para Domiciano o condenar à morte, pelo mau exemplo (Dom. 14.4). A precipitação que se segue ao espetar do ferro é sugerida pela concisão da frase: a acção do centurião que irrompe e simula estancar a ferida é expressa por particípios em dativo e um ablativo absoluto de permeio (... irrumpenti centurioni et paenula ad uulnus adposita in auxilium se uenisse simulanti...), que, colocados, na frase, entre o adjectivo que qualifica o estado do príncipe e as suas derradeiras palavras, destacadas em último lugar (semianimis adhuc... non 
aliud respondit quam: 'sero' et: 'haec est fides'), fazem coincidir o sujeito daquelas acções com o destinatário da resposta de Nero. Assim, o principal sujeito da enunciação, Nero, em quem a acção se centra, vê frustrar-se o afã do centurião, que, por breves instantes, chega tarde de mais e perde a oportunidade de capturar, com vida, o imperador caído em desgraça - como sugere a nota de que simulou vir em auxílio e as palavras sarcásticas do moribundo. Nero, finalmente liberto da ansiedade e do terror, que se adensara com a necessidade da morte, constata que escapou, in extremis, ao castigo reservado aos inimigos públicos, cuja descrição (em 49.2) o deixara conterritus. As palavras irónicas de Nero acentuam o contraste entre o alto conceito que ele tem de si e o abandono a que se vê votado.

Nero 49.4. Depois da morte, Suetónio transfere para os acompanhantes o ponto de vista das impressões e Nero torna-se a fonte dessas sensações: o olhar rígido incute horror e espanto nos presentes - é o derradeiro esgar de um monstro, de acordo com a caracterização tradicional do rosto dos tiranos, talvez influenciada pelo universo trágico. O pedido insistente para que a sua cabeça não fosse separada do corpo, satisfeito por Ícelo, liberto de Galba, é uma preocupação também de Otão (Tac. Hist. 2.49.2), cujo relato da morte retém vários pormenores em comum com Nero. Já Galba não terá essa sorte (Gal. 22).

\section{Tradução}

47.3. Assim, adiada a decisão para o dia seguinte, acordou por volta da meia noite e, quando compreendeu que o corpo da guarda militar se tinha retirado, saltou da cama e mandou procurar os amigos. E, porque não recebia resposta de nenhum, ele próprio, na companhia de uns poucos, foi buscar hospitalidade a casa de cada um. Mas como se lhe fechavam todas as portas e ninguém lhe respondia, regressou ao quarto, de onde tinham também já fugido as sentinelas, depois de terem roubado as cobertas da cama e removido a píxide do veneno. Procurou imediatamente o gladiador Espículo, ou qualquer outro sicário, para morrer às mãos dele, e, como não encontrou ninguém, «então eu - exclamou - não tenho um amigo nem um inimigo?!», e pôs-se a correr como que para se ir lançar ao Tibre.

48. Mas, pondo de novo o impulso de lado, desejou um refúgio mais afastado para recobrar o ânimo; e, como o liberto Fáon lhe oferecia a sua casa na periferia, entre as Vias Salária e Nomentana, perto do quarto marco miliário, ele, tal como estava, de pés descalços e de túnica, vestiu por cima uma capa desbotada e, depois de cobrir a cabeça e colocar um lenço na frente 
da cara, montou a cavalo na companhia de somente quatro pessoas, entre as quais se contava Esporo. 2. E, logo de seguida, aterrorizado por um tremor de terra e um relâmpago mesmo à sua frente, ouvia, dos lados do acampamento ali próximo ${ }^{8}$, o clamor dos soldados a fazerem votos contra si e em favor de Galba; e ouviu ainda um dos viajantes que encontraram a dizer «estes vão a perseguir Nero»e outro a querer saber «há novidades de Nero na Urbe?». Mas, como o cavalo se assustou com o cheiro de um cadáver lançado na rua, desvelou-se-lhe a face e ele foi reconhecido e saudado por um soldado pretoriano na reserva. 3. Chegados a um desvio, abandonaram os cavalos e, avançando através de matagal e silvas, por um carreiro de um canavial, foi a custo, e só depois de lhe ser colocada uma peça de roupa debaixo dos pés, que ele chegou à parede das traseiras da casa. Ali, perante a admoestação do tal Fáon, para que, entretanto, se fosse esconder numa cova de retirar areia, disse que não iria vivo para debaixo da terra. E, no breve compasso de espera, enquanto se preparava o acesso secreto à casa, tomou com a mão água para beber de uma poça aos seus pés e exclamou: «é esta a água fervida de Nero!»9 . 4. De seguida, com a sua capa já rasgada pelos espinhos, roçou pelos arbustos que se lhe atravessavam à frente e, agora a andar de gatas, através de uma estreita caverna escavada, recolheu ao cubículo mais próximo e deitou-se sobre uma cama provida de um modesto colchão e com um velho manto a servir de coberta. Com a fome e de novo a sede a atormentarem-no, rejeitou o pão abjecto que lhe ofereceram, mas bebeu um pouco de água tépida.

49. Então, como uns de um lado, outros do outro o instavam a furtar-se quanto antes aos ultrajes que estavam iminentes, mandou fazer uma cova à sua frente, ajustando-a exactamente à medida do seu corpo, e, ao mesmo tempo, mandou dispor bocados de mármore, se por ali se encontrassem, e também trazer água e lenha para cuidar em breve do seu cadáver, a chorar a cada ordem e a repetir sem cessar: «Que artista morro eu!». 2. Enquanto esperava, como um correio entregou uma missiva a Faón, ele arrebatou-a e leu que fora declarado inimigo pelo senado e que era procurado para ser punido segundo o costume dos antepassados. Perguntou então que género de castigo era esse; e, ao ficar a saber que se tratava de meter a cabeça de um homem, todo nu, numa furca e vergastar o corpo até à morte, agarrou,

${ }^{8} \mathrm{O}$ campo dos pretorianos.

9 Talvez uma novidade de Nero que consistiria em ferver a água antes de a refrescar com neve. 
aterrado, em dois punhais que tinha trazido consigo, verificou o gume de um e de outro e... guardou-os de novo, com o argumento de que ainda não chegara a hora marcada pelo destino. 3. E ora exortava Esporo a começar as lamentações e o pranto por ele, ora rogava a alguém que o ajudasse com o seu exemplo a entregar-se à morte. De quando em vez, censurava a sua fraqueza com estas palavras: «levo uma vida vergonhosa, uma vida ignóbil. Não é digno de Nero, não é digno. É preciso manter a cabeça no lugar em tais situações. Anda, levanta-te!». E já se aproximavam os cavaleiros, a quem tinha sido recomendado que o arrastassem vivo. Quando tal ouviu, a tremer, recitou assim:

o bater de cascos de ágeis corcéis martela-me os ouvidos!

Enterrou o ferro na garganta com a ajuda de Epafrodito, o oficial dos requerimentos. 4. Semiânime ainda, ao centurião que irrompia e lhe levava a capa à ferida, fingindo vir em seu auxílio, nada mais respondeu do que «tarde de mais!» e «isto é que é fidelidade!». E com estas palavras expirou, ficando com os olhos salientes e gélidos, ao ponto de provocar horror e espanto em quem os via. O que exigiu em primeiro lugar e com maior insistência foi que ninguém tomasse posse da sua cabeça, mas que, qualquer que fosse o modo, fosse cremado inteiro. Isto permitiu Icelo, liberto de Galba, que não muito antes fora solto da cadeia, na qual tinha sido lançado no início da revolta.

\section{Conclusão}

A narrativa é uma sinestesia encarada do ponto de vista de Nero. Há sensações visuais, de que se destaca o raio, a visão do cadáver abandonado e a leitura do despacho do senado que ele praeripuit legitque; sensações auditivas, como o tremor de terra, o clamor dos soldados, as observações dos transeuntes e o tropel dos cavalos; sensações olfactivas, como o cheiro do cadáver; sensações tácteis, como o roçar da roupa pelos arbustos e pela caverna estreita e o verificar do fio dos punhais; e, finalmente, sensações gustativas, como a água do charco, a água tépida e o pão que ele rejeitou.

Estes elementos, que apontam para efeitos de representação de carácter novelístico, fazem com que a narrativa soe a arranjo do biógrafo, ou das suas fontes. Talvez fosse inspirada num género comum na época: as "mortes de varões ilustres".

Também na morte se acentua a ligação ao teatro: esta é a última representação de Nero. Ao dizer que morre como artifex, Nero afirma a superação da mimesis pela poiesis: assume que cria arte. Só que desta vez não 
tem um condenado substituto (como no caso de Ícaro): o seu papel é insubstituível, porque representa a sua própria trama real. Pelo seu abrangente campo semântico, o termo que ele usa corresponde ao grego

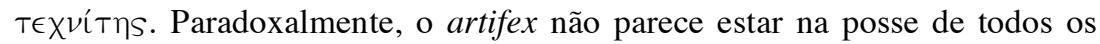
dados: a sua tragédia deriva de uma absurda necessidade da morte, a que não pode fugir, mas também do desconhecimento de vários fios do enredo que se desenrola à sua volta e que precipita o seu fim. Com efeito, ele, estranhamente, nem sequer sabe qual é o castigo destinado pelo mos maiorum a um inimigo público. Mas fica também sem resposta uma série de questões levantadas por Townend $(1967,95)$. Porque é que o grupo se aproximou da casa de modo furtivo? Porque não entraram por uma porta, ainda que lateral? Se era para ocultar a entrada aos servos de Fáon, como se poderia esperar que eles não vissem o túnel aberto na divisão? Porque não poderia Fáon oferecer comida e bebida mais agradáveis? Porque é que, de repente, se decide que não era possível manter o segredo e era urgente que Nero se suicidasse? Nero pretende ser enterrado ou cremado? Porque é que, depois de todas as precauções, a cavalaria pretoriana se dirige para a casa e descobre imediatamente o imperador moribundo? Tudo aponta para uma traição não explícita. Será que o soldado na reserva, que reconheceu Nero no caminho, deduziu, pelos acompanhantes, o local para onde ele se dirigia? O cursor estaria a par dos acontecimentos e revelaria o paradeiro de Nero? Não sabemos. Há uma série de circunstâncias de que não conhecemos as causas. O biógrafo está mais preocupado com os efeitos sobre a personagem do que com os motivos que os geram. Através da focalização interna na personagem de Nero, o leitor tem acesso às percepções do imperador em fuga e não mais. Assim o leitor poderá sentir melhor o drama do imperador, pela insuficiência da informação que ele possuía. Mas, por outro lado, a exploração das reacções e ditos do imperador é a forma que a biografia encontra para analisar o carácter, deixando de parte importantes dados da história política (cf. Plu. Alex. 1).

A seguir a este trecho vem a descrição do funeral - dispendioso, como o fora a vida. É de notar a presença das amas, e sobretudo da concubina Acte, que depositam os restos mortais no sepulcro dos Domícios (Nero 50). Acte retribui assim o verdadeiro amor que Nero tinha por ela.

Depois das rubricas relativas ao aspecto físico, estudos, gostos, religião, Suetónio termina esta Vida com as reacções paradoxais perante a morte de Nero, reveladoras do quanto este imperador era, ao mesmo tempo, odiado e amado. Por um lado, o gaudium público, pela libertação: a plebe 
corre pilleata, isto é, com o barrete característico da libertação dos escravos e das Saturnais (Nero 57.1) e o símbolo da libertação da tirania (os cesaricidas cunharam moedas com o pileus circundado por dois punhais).

Por outro lado, há manifestações secretas de pesar: deposição anual de flores sobre o túmulo; retratos nos rostra; escritos com promessas de retorno, para ruína dos seus inimigos. De tal modo que, passados vinte anos, um falso Nero ainda teve grande acolhimento, sobretudo entre os Partos, o que revela a admiração que o Oriente lhe consagrava (Nero 57.2). Nero conseguiu, afinal, realizar a ambição de perpetuar a fama. E outros imperadores (Otão e Vitélio), no conturbado ano e meio que se segue, irão tentar imitar algumas acções deste príncipe, que, desde 54 d.C., seduziu o povo com a sua proximidade e os seus dotes histriónicos e atraiu sobre si o ódio dos senadores, os guardiães da moral tradicional. Era, sem dúvida, jovem e vaidoso, mas muita da apreciação desfavorável das suas realizações não é a causa, mas o resultado da sua queda, em Junho de 68.

\section{Bibliografia}

Bartsch, S., Actors in the audience. Theatricality and doublespeak from Nero to Hadrian, Cambridge (Mass.), Harvard University Press, 1994.

Bradley, K. R., Suetonius' Life of Nero. An historical commentary, Bruxelles, Latomus, 1978.

Brunt, P. A., "The revolt of Vindex and the fall of Nero", Latomus 18 (1959) 531-559.

D’Anna, G., Le idee letterarie di Suetonio, Firenze, La Nuova Italia, 1954.

Frazer, R. M., "Nero the artist-criminal", CJ 62 (1966) 17-20.

Lorenzo, E. di, “A proposito dell'espressione neroniana qualis artifex pereo (Suet., Nero 49)", Studi salernitani in memoria di R. Cantarella a cura di Gallo I., Univ. di Salerno, 1981, 523-535.

Lounsbury, R. C., The Arts of Suetonius: An Introduction, New York, Lang, 1987.

- - - "Inter quos et Sporus erat: The making of Suetonius' Nero", ANRW II, 33, 5 (1991) 3748-3779.

Townend, G. B., "Suetonius and his influence", in Dorey, T. A.. (ed.), Latin biography, London, Routledge \& Kegan Paul, 1967, 79-111.

Warmington, B. H., Suetonius Nero. Text, with intr. \& notes, London, Bristol Classical Press, ${ }^{2} 1999$.

JOSÉ LUÍS L. BRANDÃO 